\title{
Nilai Prediktif Persepsi Maternal Terhadap Status Nutrisi Anak Usia 0-2 Tahun
}

\author{
Putu Satya Pratiwi, ${ }^{*}$ Ni Made Chandra Mayasari, ${ }^{*}$ Ni Luh Putu Ariastuti, ${ }^{* *}$ I Gusti Lanang Sidiartha*** \\ "Bagian Ilmu Kesehatan Anak RSU Dharma Yadnya, Denpasar, "*Bagian IKK/IKP ***Bagian Ilmu Kesehatan AnakFakultas Kedokteran \\ Universitas Udayana/RSUP Sanglah, Denpasar
}

Latar belakang. Ibu merupakan subjek pertama yang mengenali permasalahan kesehatan anak sehingga persepsi maternal yang baik terkait permasalahan gizi anak, memungkinkan identifikasi dini dan tatalaksana yang sesuai.

Tujuan. Studi ini bermaksud untuk menilai sejauh mana ketepatan persepsi ibu akan keadaan malnutrisi pada anak.

Metode. Penelitian ini merupakan studi potong-lintang analitik yang melibatkan sebanyak 84 ibu yang memiliki anak berusia 0 hingga 2 tahun di wilayah kerja Puskesmas IV Denpasar Selatan.

Hasil. Rerata usia ibu adalah 28,27 tahun, sebanyak 55,9\% merupakan lulusan SMA/sederajat, dan 65,5\% tidak bekerja. Rerata usia anak adalah 7,98 bulan, 57,1\% anak laki-laki. Prevalensi anak dengan status gizi kurang, gizi lebih dan stunting masing-masing sebesar 8,3\%, 9,5\% dan 7,1\%. Nilai prediktif positif dan negatif persepsi ibu terhadap status nutrisi anak gizi kurang, gizi lebih, dan stunting berturut-turut adalah 25\%, 20\%, 0\% dan 93,4\%, 94,9\% dan $92,1 \%$.

Kesimpulan. Persepsi ibu dalam mengeksklusi gangguan nutrisional pada anak lebih bisa diyakini oleh klinisi, dibandingkan dalam mengidentifikasi. Inadekuasi persepsi ibu dalam mengidentifikasi kejadian malnutrisi masih cukup jamak, menyebabkan pentingnya partisipasi aktif dari penyedia layanan kesehatan dalam mengidentifikasi dan menangani malnutrisi pada anak. Sari Pediatri 2020;21(6):352-7

Kata kunci: nilai prediktif, status nutrisi, antropometri

\section{Predictive Value of Maternal Perception of the Nutritional Status of Children Age 0-2 Years}

\author{
Putu Satya Pratiwi, ${ }^{*}$ Ni Made Chandra Mayasari, ${ }^{*}$ Ni Luh Putu Ariastuti, ${ }^{* *}$ I Gusti Lanang Sidiartha***
}

Background. Mothers are the first subjects to recognize children's health problems, so good maternal perceptions related to child nutrition problems, allow early identification and appropriate management.

Objective. This study intends to assess the accuracy of the mother's perception of the state of malnutrition in children.

Methods. This research is an analytic cross-sectional study involving 84 mothers with children aged 0 to 2 years in the working area of Puskesmas IV South Denpasar.

Result. The mean age of mothers is 28.27 years, as many as $55.9 \%$ are high school graduates / equivalent, and $65.5 \%$ are unemployed. The mean age of children was 7.98 months, $57.1 \%$ of boys. The prevalence of children with poor nutritional status, over nutrition and stunting were $8.3 \%, 9.5 \%$ and $7.1 \%$, respectively. Positive predictive value and negative predictive value of the mother's perception of the nutritional status of children lacking nutrition, over nutrition and stunting are $25 \%, 20 \%, 0 \%$ and $93.4 \%, 94.9 \%$ and $92.1 \%$. Conclusion. Maternal perceptions in excluding nutritional disorders in children are more believable by clinicians, than in identifying. The inadequate perception of mothers in identifying the occurrence of malnutrition is still quite high, causing the importance of active participation of health care providers in identifying and managing malnutrition in children. Sari Pediatri 2020;21(6):352-7

Keywords: predictive value, nutritional status, anthropometry

Alamat korespondensi: Putu Satya Pratiwi. RSU Dharma Yadnya, Jl. WR. Supratman No. 256, Kesiman Kertalangu, Kec. Denpasar Timus, Denpasar, Bali 80237. Email: pratiwisatya@gmail.com 


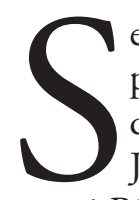
ektor kesehatan merupakan salah satu program prioritas pembangunan bangsa yang telah diikutkan ke dalam Rencana Pembangunan Jangka Menengah Nasional (RJPMN). ${ }^{1}$ Hasil survei Riset Kesehatan Dasar (Riskesdas) pada tahun 2018 mendapatkan adanya penurunan prevalensi gizi kurang dan gizi buruk, tetapi capaian ini belum sukses memenuhi target RJPMN pada tahun 2019.1,2 Pada lingkup global, Indonesia dan negara-negara Asia Selatan, merupakan salah satu negara dengan prevalensi stunting tertinggi, yaitu stunting ditemukan pada satu dari tiga anak. ${ }^{3}$ Kajian gizi oleh UNICEF menyatakan salah satu hambatan utama terhadap peningkatan gizi dan perkembangan anak di Indonesia adalah ketidaktahuan orang akan permasalahan gizi sebagai sebuah masalah. Permasalahan anak pendek dan gizi ibu masih merupakan permasalahan yang tidak mudah dilihat. ${ }^{4}$ Studi oleh Putri $\mathrm{dkk}^{5}$ menunjukkan adanya hubungan yang bermakna antara persepsi ibu dan status nutrisi anak berusia di bawah lima tahun.

Periode dua tahun pertama kehidupan memengaruhi kenaikan berat badan dan panjang badan secara dramatis, yaitu sejak lahir hingga usia 2 tahun, 50\% dari tinggi badan dewasa akhir, serta $20 \%$ berat badan dewasa ditentukan. ${ }^{6-9}$ Selain itu, dalam interval yang sama, otak mencapai $80 \%$ ukuran dewasa, dan pada usia 6 tahun berukuran 95\% dari otak dewasa. ${ }^{67,9}$ Proses akselerasi pertumbuhan ini menjadikan periode dua tahun pertama seorang anak menjadi sangat rentan akan permasalahan nutrisi. Persepsi ibu akan status nutrisi anaknya dapat mendorong atau membatasi pemberian makanan. ${ }^{10}$

Persepsi seorang ibu dalam mengidentifikasi gangguan nutrisi seorang anak menjadi penting., Hal tersebut akan menentukan sebagai acuan klinisi untuk manajemen nutrisi yang tepat atau tetap tidak mengetahui permasalahan status gizi yang ada. Untuk itu, penelitian ini bermaksud untuk mengetahui nilai prediktif persepsi ibu dalam mengidentifikasi serta mengeksklusi gangguan nutrisi pada ana berusia 0 hingga 2 tahun. Selain itu, studi ini juga bermanfaat sebagai studi pendahuluan untuk menilai persentase gangguan nutrisi pada anak berusia 0-2 tahun di wilayah kerja Puskesmas IV Denpasar Selatan.

\section{Metode}

Studi potong-lintang ini dilaksanakan di Pusat Kesehatan Masyarakat (Puskesmas) IV Denpasar
Selatan, Bali. Pemilihan Puskesmas ditentukan berdasarkan randomisasi dari 11 Puskesmas di kota Denpasar. Anak berusia 0 hingga 2 tahun yang berkunjung ke Puskesmas untuk berobat maupun imunisasi diikutkan ke dalam studi ini, dan dipilih berdasarkan teknik sampling acak. Pengumpulan data dilakukan pada 28 Mei 2019, 15 Juli 2019 dan 15 Agustus 2019. Dengan penggunaan rumus hitung sampel untuk studi potong-lintang, dihitung berdasarkan proporsi stunting di Indonesia, yaitu sebesar 30,8\%. Didapatkan jumlah minimal sampel untuk studi ini adalah 35 subjek.

Studi ini telah disetujui oleh Kepala Puskesmas IV Denpasar Selatan dan ibu dari seluruh peserta penelitian menyetujui untuk diikutkan ke dalam studi dengan menandatangani informed consent.

Data subjek penelitian diperoleh berdasarkan wawancara dan pengukuran antropometri yang dikerjakan oleh dokter. Wawancara terhadap ibu dilakukan menggunakan intrumen kuesioner yang terdiri atas identitas ibu dan anak, total jumlah anak dalam keluarga, tingkat pendidikan ibu, status pekerjaan ibu, dan penghasilan keluarga. Total jumlah anak dalam keluarga dikelompokkan menjadi 1-2 anak atau lebih dari 2. Tingkat pendidikan ibu diklasifikasikan menjadi rendah (SMP dan lebih rendah) atau tinggi (SMA dan lebih tinggi). Pendapatan keluarga dikelompokkan berdasarkan Upah Minimum Kota (UMK) Denpasar tahun 2019 untuk kedua orangtua, rendah (dibawah $\mathrm{Rp} 5.106 .000$ ) atau tinggi (Rp 5.106.000 dan lebih). Wawancara terkait persepsi ibu akan status nutrisi anaknya disajikan dalam tiga buah pertanyaan. Ibu diminta menilai apakah anak tampak kurus, apakah anak tampak gemuk, dan apakah anak terlihat pendek. Dalam pertanyaan tersebut ibu menilai dengan jawaban "ya" atau "tidak".

Pengukuran tinggi dan berat badan dilakukan untuk memperoleh data antropometri dari seluruh subjek. Berat badan diukur menggunakan timbangan berat terkalibrasi, dengan subjek menggunakan pakaian yang minimal. Panjang badan dilakukan dalam posisi terlentang dengan penggunakan papan panjang badan. Pengukuran panjang badan terlentang dilakukan ketika anak berbaring terlentang dengan kepala menempel terhadap kepala papan yang terfiksasi, menekan rambut, mata menatap lurus ke atas, kaki lurus, dan telapak kaki menempel terhadap kaki papan. Hasil pengukuran diplotkan pada kurva pertumbuhan WHO 2005 untuk menentukan status 
nutrisi berat badan berdasarkan tinggi badan (BB/ $\mathrm{TB})$ dan panjang badan berdasarkan usia $(\mathrm{PB} / \mathrm{U})$. $\mathrm{BB} /$

TB diklasifikasikan menjadi gizi kurang $(\mathrm{BB} / \mathrm{TB}<-2$ $\mathrm{SD})$, gizi lebih $(\mathrm{BB} / \mathrm{TB}>+2 \mathrm{SD})$ dan gizi baik $(-2 \leq$ $\mathrm{BB} / \mathrm{TB} \leq+2)$. Panjang badan menurut umur $(\mathrm{PB} / \mathrm{U})$ diklasifikasikan menjadi stunting $(\mathrm{PB} / \mathrm{U}<-2 \mathrm{SD})$ dan tinggi badan normal $(\mathrm{PB} / \mathrm{U} \geq-2 \mathrm{SD})$.

Data karakteristik ibu dan anak disajikan dalam bentuk tabel frekuensi. Persepsi ibu akan status nutrisi anak (gizi kurang, gizi lebih, dan stunting) dan hasil pengukuran antropometri masing-masing disajikan dalam bentuk tabulasi silang dengan frekuensi dan persentase untuk setiap kategori.

\section{Hasil}

Kami melakukan pemeriksaan terhadap 91 anak selama studi penelitian (Mei 2019 hingga Agustus 2019), sebanyak 7 sampel drop out karena data yang kurang lengkap. Dengan demikian, sebanyak 84 anak berusia 0-2 tahun diikutkan di dalam penelitian ini. Median usia subjek adalah 8,19 (range 0,29-22,55) bulan dengan proporsi anak laki-laki dan perempuan yang hampir proporsional. Karakteristik subjek tertera pada Tabel 1.

Prevalensi anak dengan status gizi kurang, gizi lebih dan stunting berturut-turut sebesar 8,3\%, 9,5\% dan $7,1 \%$.

Uji kemaknaan status nutrisi gizi kurang dan gizi lebih berdasarkan persepsi ibu dibandingkan dengan hasil pemeriksaan berdasarkan status antropometri (berat badan menurut tinggi badan) sebagai gold standard tertera pada Tabel 2 dan 3. Dalam menilai adanya gangguan nutrisi berupa gizi kurang didapatkan persepsi ibu memiliki nilai prediksi positif sebesar $25 \%$, nilai prediksi negatif $93,42 \%$, sensitifitas $28,6 \%$, spesifisitas $92,2 \%$ dan memiliki akurasi $86,9 \%$.

Dalam menilai adanya gangguan nutrisi berupa gizi lebih, didapatkan persepsi ibu memiliki nilai prediksi positif sebesar $20 \%$, nilai prediksi negatif $94,9 \%$, sensitifitas $62,5 \%$, spesifisitas $73,6 \%$ dan memiliki akurasi $72,6 \%$.

Uji kemaknaan stunting atau perawakan pendek berdasarkan persepsi ibu dibandingkan dengan hasil pemeriksaan berdasarkan status antropometri (berat badan menurut tinggi badan) sebagai gold standard tertera pada Tabel 4. Dalam menilai anak yang

\begin{tabular}{|c|c|c|c|}
\hline Karakteristik & Rerata & Jumlah (n) & Persentase (\%) \\
\hline Usia ibu (tahun) & 28,27 & & \\
\hline \multicolumn{4}{|l|}{ Pendidikan ibu } \\
\hline SD & & 3 & 3,6 \\
\hline SMP & & 14 & 16,7 \\
\hline SMA, SMK & & 47 & 55,9 \\
\hline Diploma & & 8 & 9,5 \\
\hline Perguruan tinggi & & 12 & 14,3 \\
\hline \multicolumn{4}{|l|}{ Pekerjaan ibu } \\
\hline Bekerja & & 29 & 34,5 \\
\hline Tidak bekerja & & 55 & 65,5 \\
\hline Penghasilan keluarga (rupiah) & 4.373 .810 & & \\
\hline Tinggi & & 18 & 21,4 \\
\hline Rendah & & 66 & 78,6 \\
\hline \multicolumn{4}{|l|}{ Jenis kelamin } \\
\hline Perempuan & & 36 & 42,9 \\
\hline Laki-laki & & 48 & 57,1 \\
\hline Usia anak (bulan) & 8,64 & & \\
\hline \multicolumn{4}{|l|}{ Jumlah anak (orang) } \\
\hline 1 & & 36 & 42,9 \\
\hline 2 & & 32 & 38,1 \\
\hline 3 & & 14 & 16,6 \\
\hline$>3$ & & 2 & 2,4 \\
\hline
\end{tabular}


Putu Satya Pratiwi dkk: Nilai prediktif persepsi maternal terhadap status nutrisi anak usia 0-2 tahun

Tabel 2. Tabulasi silang antara distribusi status nutrisi anak gizi kurang berdasarkan persepsi ibu dan status antropometri

\begin{tabular}{lcccccc}
\hline $\begin{array}{l}\text { Persepsi gizi } \\
\text { kurang }\end{array}$ & \multicolumn{3}{c}{ Status antropometri } & Jumlah & \multirow{2}{*}{$(\%)$} \\
\cline { 2 - 6 } & $\begin{array}{c}\text { Positif } \\
(\mathrm{BB} / \mathrm{TB}<-2 \mathrm{SD})\end{array}$ & $(\%)$ & $\begin{array}{c}\text { Negatif } \\
(\mathrm{BB} / \mathrm{TB} \geq-2 \mathrm{SD})\end{array}$ & $(\%)$ & & \\
\hline Positif & 2 & 2,4 & 6 & 7,1 & 8 & 9,5 \\
Negatif & 5 & 6,0 & 71 & 84,5 & 76 & 90,5 \\
Jumlah & 7 & 8,4 & 77 & 91,6 & 84 & 100 \\
\hline
\end{tabular}

Keterangan: nilai prediksi positif $=25 \%$, nilai prediksi negatif $=93,4 \%$

Tabel 3. Tabulasi silang antara distribusi status nutrisi anak gizi lebih berdasarkan persepsi ibu dan status antropometri

\begin{tabular}{lcccccc}
\hline Persepsi Gizi & \multicolumn{3}{c}{ Status Antropometri } & Jumlah & \multirow{2}{*}{ (\%) } \\
\cline { 2 - 5 } & $\begin{array}{c}\text { Positif } \\
(\mathrm{BB} / \mathrm{TB} \geq+2 \mathrm{SD})\end{array}$ & $(\%)$ & $\begin{array}{c}\text { Negatif } \\
(\mathrm{BB} / \mathrm{TB}<+2 \mathrm{SD})\end{array}$ & $(\%)$ & & \\
\hline Positif & 5 & 6,0 & 20 & 23,8 & 25 & 29,8 \\
Negatif & 3 & 3,5 & 56 & 66,7 & 59 & 70,2 \\
Jumlah & 8 & 9,5 & 76 & 90,5 & 84 & 100 \\
\hline
\end{tabular}

Keterangan: nilai prediksi positif $=20 \%$, nilai prediksi negatif $=94,9 \%$

Tabel 4. Tabulasi silang antara distribusi anak pendek lebih berdasarkan persepsi ibu dan status antropometri

\begin{tabular}{lcccccc}
\hline $\begin{array}{l}\text { Persepsi anak } \\
\text { pendek }\end{array}$ & \multicolumn{3}{c}{ Status antropometri } & Jumlah & (\%) \\
\cline { 2 - 5 } & $\begin{array}{c}\text { Positif } \\
(\mathrm{TB} / \mathrm{U}<-2 \mathrm{SD})\end{array}$ & $(\%)$ & $\begin{array}{c}\text { Negatif } \\
(\mathrm{TB} / \mathrm{U} \geq-2 \mathrm{SD})\end{array}$ & $(\%)$ & & \\
\hline Positif & 0 & 0,0 & 8 & 9,5 & 8 & 9,5 \\
Negatif & 6 & 7,1 & 70 & 83,4 & 76 & 90,5 \\
Jumlah & 6 & 7,1 & 78 & 92,9 & 84 & 100 \\
\hline
\end{tabular}

Keterangan: nilai prediksi positif $=0 \%$, nilai prediksi negatif $=92,1 \%$

memiliki tinggi badan kurang, didapatkan persepsi ibu memiliki nilai prediksi positif sebesar $0 \%$, nilai prediksi negatif $92,1 \%$, sensitifitas $0 \%$, spesifisitas $89,74 \%$ dan memiliki akurasi 83,3\%.

\section{Pembahasan}

Penelitian ini dilakukan untuk mengetahui prediksi positif persepsi ibu dalam menilai gangguan nutrisional pada anaknya, dibandingkan dengan hasil pemeriksaan antropometri sebagai gold standard untuk menilai status nutrisi gizi kurang, gizi lebih, dan stunting.

Penelitian ini merupakan uji diagnostik dengan mempertimbangan jumlah sampel yang kecil dan aspek kepraktisan. Oleh sebab itu, nilai prediksi positif (NPP)/nilai duga positif (NDP) pada penelitian ini lebih ditekankan. Bagi klinisi, NDP memiliki makna yang lebih penting dibandingkan dengan sensitivitas dan spesifisitas Ketika hasil pemeriksaan tiba di klinisi, klinisi akan berpikir berapa kemungkinan hasil tersebut memang benar-benar positif. ${ }^{11}$ Dalam situasi klinis, anggapan ibu yang cenderung menganggap bahwa anaknya memiliki status nutrisi yang baik akan mengurangi kemungkinan dilakukannya pemeriksaan status antropometri. Studi oleh Arpini $\mathrm{dkk}^{10}$ menunjukkan bahwa persepsi ibu terkait berat badan anak dikaitkan dengan praktik pemberian makan anak, khususnya pembatasan dan/atau dorongan untuk makan.

Dalam studi ini didapatkan $16,1 \%$ ibu dari anak dengan berat badan normal cenderung meremehkan status nutrisi anak mereka. Sementara 40,4\% dari ibu cenderung untuk menaksirkan terlalu tinggi. Taksiran yang terlalu tinggi maupun terlalu rendah terhadap status nutrisi anak dengan berat badan normal merupakan sesuatu yang serius,. Kondisi tersebut menyebabkan ketidakpuasan ibu. Kesan kurus atau gemuk tersebut menentukan sikap ibu terkait asupan makanan dalam upaya meningkatkan atau menurunkan berat badan pada anak yang sehat. ${ }^{10,12,13}$ 
Nilai diagnostik untuk persepsi gizi kurang ibu memiliki sensitivitas $28,6 \%$, spesifisitas $92,2 \%$ dan nilai prediksi positif $25 \%$. Nilai prediksi negatif $93,4 \%$ dan memiliki akurasi $86,9 \%$ dalam menilai gizi kurang. NPN yang mendekati $100 \%$ dalam penelitian ini menunjukkan rendahnya kejadian negatif palsu. Implikasinya adalah ketika ibu berpersepsi bahwa anak tidak mengalami gizi kurang, besar kemungkinan bahwa anak memang tidak mengalami gizi kurang berdasarkan pemeriksaan antropometri. Dengan demikian, kemampuan ibu dalam mengeksklusi lebih bisa dipercaya dibandingkan dalam "mendiagnosis" gizi kurang pada anaknya. Ibu memiliki kemampuan lebih baik dalam memastikan bahwa anak tidak gizi kurang, tetapi klinisi harus lebih berhati-hati dalam menggunakan persepsi ibu dalam mendeteksi gizi kurang.

Duarte $^{14}$ mendapatkan bahwa ibu dari anak underweight cenderung untuk menilai terlalu tinggi status nutrisi anak mereka, sementara pada ibu dengan anak overweight adalah sebaliknya. Persepsi ibu akan berbeda, tergantung pada status nutrisi anaknya. ${ }^{14}$ Selain itu, adanya hubungan antara jenis kelamin anak dan persepsi ibu untuk status nutrisi anaknya, dimana orangtua cenderung untuk tidak mengenali overweight pada anak laki-laki dan cenderung untuk overestimasi berat badan anak perempuan. ${ }^{15,16}$

Persepsi ibu akan gizi lebih, dalam uji diagnostik ini menunjukkan NPP sebesar 20\%, NPN 94,9\%, sensitivitas $62,5 \%$ dan spesifisitas $73,68 \%$. Nilai NPN yang cenderung mendekati $100 \%$ menunjukkan rendahnya kejadian negatif palsu, nilai ini menunjukkan kemampuan ibu dalam memastikan anaknya tidak mengalami overweight maupun obesitas lebih bisa diyakini oleh klinisi, dibandingkan persepsi ibu bahwa benar anak mengalami gizi lebih.

Beberapa studi sebelumnya menunjukkan bahwa ibu memiliki kesulitan dalam mengenali overweight atau obesitas pada anak mereka, ${ }^{15,16,18}$ ketika mereka cenderung untuk mengunderestimasi berat badan berlebih. ${ }^{18}$ Beberapa bukti juga menunjukkan bahwa persepsi keliru tersebut cenderung lebih umum ditemukan pada ibu yang overweight, ${ }^{21,22}$ memiliki tingkat pendidikan yang rendah, ${ }^{21,22} \mathrm{ibu}$ dari anak laki-laki ${ }^{22}$ dan anak yang lebih muda. ${ }^{23}$ Studi oleh Binkin $\mathrm{dkk}^{17}$ menunjukkan bahwa tingkat meremehkan status nutrisi diamati pada daerah dengan prevalensi obesitas yang tinggi. Pada studi ini, $79,7 \%$ ibu berpendidikan tinggi (minimal tamat
SMA) sehingga lebih banyak ibu memiliki persepsi yang benar untuk berat badan anak mereka, meskipun populasi dalam studi ini memiliki tingkat obesitas yang lebih tinggi $(9,5 \%)$ dibandingkan dengan proporsi nasional $(8,0 \%){ }^{2}$

Dalam menilai apakah anak pendek atau stunting, persepsi ibu memiliki hasil uji diagnostik sebagai berikut: NPP sebesar 0\%, NPN 92,6\%, dengan sensitivitas $0 \%$ dan spesifisitas $89,7 \%$. Nilai NPP sebesar 0\% menunjukkan bahwa seluruh persepsi ibu bahwa anak pendek adalah positif palsu. Nilai NPN sebesar 91,1\% menunjukkan bahwa $91,1 \%$ ibu tepat dalam memprediksi anak bebas stunting, ketika anak benar-benar tidak mengalami stunting berdasarkan pemeriksaan antropometri. Pada tabulasi-silang, sebanyak $6(7,1 \%)$ anak yang justru stunting dinilai sebagai normal oleh ibu.

Prevalensi stunting dalam studi ini adalah sebesar $7,1 \%$, lebih rendah dibandingkan prevalensi nasional sebesar 30,8\%. ${ }^{2}$ Berdasarkan analisis oleh Titaley ${ }^{24}$, anak dari luar daerah Jawa dan Bali cenderung untuk mengalami stunting lebih tinggi dibandingkan dengan anak yang tinggal di daerah Jawa dan Bali, khususnya yang berasal dari bagian Timur Indonesia. Selain itu, jumlah anggota keluarga dan jumlah anak bawah lima tahun (balita) dalam keluarga juga merupakan faktor signifikan, yang menyebabkan alokasi makanan dan sumber daya dalam keluarga menyebabkan kesehatan yang buruk dan status nutrisi yang sub-optimal.

\section{Kesimpulan}

Hampir seluruh dari ibu meyakini bahwa anak mereka memiliki berat badan maupun tinggi badan yang cukup, terlepas dari status nutrisinya, dan lebih dari setengahnya memiliki persepsi yang buruk terhadap status nutrisi anak mereka. Dari keseluruhan ibu dengan persepsi yang buruk, kebanyakan ibu cenderung untuk mengoverestimasikan status nutrisi, terutama bila anak tersebut overweight.

Hal ini mengharuskan pemberi layanan kesehatan mengkaji kembali pendapat ibu terkait status nutrisi anaknya, melakukan pemeriksaan tinggi dan berat badan, dan paling penting, membimbing ibu dalam memahami arti dari berat badan dan tinggi badan sesuai usia anak, sehingga ibu memiliki persepsi yang tepat. 
Putu Satya Pratiwi dkk: Nilai prediktif persepsi maternal terhadap status nutrisi anak usia 0-2 tahun

\section{Daftar pustaka}

1. Badan Perencanaan Pembangunan Nasional. Rencana Pembangunan Jangka Menengah Nasional (RPJMN) 20152019. Jakarta: Kementerian PP N/Bappenas Republik Indonesia; 2015.

2. Kementerian Kesehatan Republik Indonesia. Hasil utama Riset Kesehatan Dasar (Riskesdas) 2018. Jakarta: Badan Penelitian dan Pengembangan Kesehatan Kemkes RI; 2018.

3. UNICEF, WHO, World Bank. Prevalence of stunting, height for age (\% of children under 5). UNICEF, WHO, World Bank: Joint child malnutrition estimates (JME) 2015. Diunduh 25 Desember 2019. Didapat dari: URL: http://data.worldbank. org/indicator/SH.STA.STNT.ZS.

4. UNICEF. Infant and young child feeding. UNICEF 2012. Diunduh 25 Desember 2019. Didapat dari: URL: https://www. unicef.org/nutrition/files/Final_IYCF_programming_guide_ June_2012.pdf.

5. Putri K. M. Hubungan pengetahuan dan persepsi dengan status gizi balita di Puskesmas Paal Merah I Kota Jambi tahun 2017. Jurnal kebidanan 2018;4:15.

6. Bier DM. Growth in the first two years of life. Dalam: Barker DJP, Bergmann RL, Ogra PL, penyunting. The window of opportunity: pre-pregnancy to 24 months of age. Nestle Nutr Workshop Ser Pediatr Program. Switzerland: Nestle Ltd; 2008.h.135-144.

7. Clayton PE, Gill MS. Normal growth and its endocrine control. Dalam: Brook CDG, Hindmarsh PC, Jacobs HS. Clinical pediatric endocrinology. Edisi keempat. London: Blackwell Science; 2001.h. 95-114.

8. Centers for Disease Control and Prevention. CDC Growth Charts 2000. United States. Diunduh 2 November 2019. Didapat dari: URL: http://www. cdc.gov/growthcharts/.

9. de Onis M, Garza C, Onyango AW. Comparison of the WHO child growth standards and the CDC 2000 growth charts. J Nutr 2007;137:144-8.

10. Arpini LSB, Barbosa GC, Justo GF, Salaroli LB, Molina $\mathrm{MCB}$. Association between maternal perception of children's nutritional status and diet quality of schoolchildren. Demetra 2015;10;299-314.

11. Sastroasmoro S, Ismael S. Dasar-dasar metodologi penelitian klinis. Balai Penerbit Bagian Ilmu Kesehatan Anak, Fakultas Kedokteran, Universitas Indonesia; 1995.

12. Aparicio G, Cunha M, Duarte J, Pereira A, Albuquerque C.
Nutritional status in preschool children: current trends of mother's body perception and concerns. Atencion Primaria 2013; 45:194-200.

13. Webber L, Cooke L, Hill C, Wardle J. Child adiposity and maternal feeding practices: a longitudinal analysis. Am J Clin Nutr 2010; 92:1423-8.

14. Duarte LS, Fujimori E, Toriyama ATM, Palombo CNT, Miranda PPL, Borges ALV. Maternal perception of their child's nutritional status at less than three years old. Rev Esc Enferm USP 2016;50:771-8.

15. Francescatto C, Santos NS, Coutinho VF, Costa RF. Mothers' perceptions about the nutritional status of their overweight children: a systematic review. J Pediatr (Rio J) 2014;90:33243.

16. Chuproski P, Mello DF. Mother's perception of their children's nutritional status. Rev Nutr 2009;22:929-36.

17. Binkin N, Spinelli A, Baglio G, Lamberti A. What is common becomes normal: the effect of obesity prevalence onmaternal perception. Nutr Metab Cardiovasc Dis 2013;23:410-631.

18. Rietmeijer-Mentink M, Paulis WD, Middelkoop M, Bindels PJ, van der Wouden JC. Difference between parental perception and actual weight status of children: a systematic review. Matern Child Nutr 2013;9:3-22.

19. Warschburger P, Kröller K. Maternal perception of weight status and health risks associated with obesity in children. Pediatrics 2009;124:60-8.

20. Manios Y, Moschonis G, Grammatikaki E, Anastasiadou A, Liarigkovinos T. Determinants of childhood obesity and association with maternal perceptions of their children's weight status: the "GENESIS" study. J Am Diet Assoc 2010;110:1527-31.

21. Baughcum AE, Chamberlin LA, Deeks CM, Powers SW, Whitaker RC. Maternal perceptions of overweight preschool children. Pediatrics 2000;106:1380-6.

22. He M, Evans A. Are parents aware that their children are overweight or obese? Do they care? Can Fam Physician 2007;53:1493-9.

23. Eckstein KC, Mikhail LM, Ariza AJ, Thomsonc JS, Millardd SC, Binns HJ. Parents' perceptions of their child's weight and health. Pediatrics 2006;117:681-90.

24. Titaley CR, Ariawan I, Hapsari D, Muasyaroh A, Dibley M J. Determinants of the stunting of children under two years old in Indonesia: a multilevel analysis of the 2013 Indonesia basic health survey. Nutrients 2013;11:1106. 